\title{
EVOLUÇÃO DOS ADESIVOS DENTÁRIOS: revisão de literatura
}

\author{
Hayanne Gabrielle Kimura FERNANDES* \\ Millena Aparecida de Souza MARINHO** \\ Estella Maris PEREIRA*** \\ José Carlos Rabelo RIBEIRO****
}

Marcos Ribeiro MOYSÉS******

\begin{abstract}
*Inapós/graduanda/Curso de Graduação em Odontologia, hay_odonto@hotmail.com
**Inapós/graduando/ Curso de Graduação em Odontologia, millenaasmarinho@ hotmail.com

***Inapós/graduanda/ Curso de Graduação em Odontologia, estella.emp@ hotmail.com

****Inapós e UninCor/Docente/ Curso de Graduação em Odontologia, professorcae@gmail.com

*****Inapós e UninCor/Docente/ Curso de Graduação em Odontologia, marcos.ribeiro.moise@ terra.com.
\end{abstract}

Recebido em: 12/07/2015 - Aprovado em: 17/08/2016 - Disponibilizado em: 18/12/2016

\begin{abstract}
RESUMO:
A odontologia restauradora sofreu uma grande evolução nos últimos anos, a grande demanda pela estética por parte dos pacientes, levou a necessidade da criação de produtos cada vez melhores. Os sistemas adesivos apresentam grande importância no processo restaurador, atuando como barreira protetora, selando os canalículos dentinários, e auxiliando na adesão do material restaurador à estrutura dental. No mercado odontológico dos dias atuais, é possível encontrar sistemas adesivos convencionais, que precisam do condicionamento com ácido fosfórico previamente a aplicação do adesivo; os sistemas autocondicionantes, que dispensam a aplicação do ácido, por já apresentarem monômeros ácidos na formula do primer; e o sistema adesivo universal, recentemente lançado no mercado, que pode ser utilizado em qualquer uma das técnicas anteriores, com também no condicionamento seletivo de esmalte. As pesquisas em relação aos adesivos dentários para que possam ser utilizados em qualquer técnica adesiva, devem continuar para que as limitações presentes nos sistemas atuais possam ser ultrapassadas, a fim de se chegar cada vez mais próximo do produto ideal.
\end{abstract}

Palavras-chave: Adesivos. Odontologia restauradora. Materiais dentários. Dentística. Compósitos dentários.

\section{EVOLUTION OF DENTAL ADHESIVES: review of literature}

\begin{abstract}
:
The restorative dentistry have been many developments in recent years, the high demand for aesthetic by patients, led to the need to create better and better products. The adhesive systems are extremely important in the healing process, acting as a protective barrier, sealing the dentinal tubules, and assisting in the adhesion of restorative material to the tooth structure. In the dental market of today, you can find conventional adhesive systems, which need the phosphoric acid etching prior to application of the adhesive; the self-etching systems, which do not require the application of acid, as there were already acidic monomers in the formula of the primer; and universal adhesive system recently launched on the market that can be used in any of the preceding techniques, also in the selective etching of enamel. The searches in relation to the dental adhesives that may be used in any adhesive technique should continue to limitations present in existing systems can be overcome in order to get closer and closer the ideal product.
\end{abstract}

Key words: Adhesives. Restorative dentistry. Dental materials. Dentistry. Dental composites. 


\section{Introdução}

A odontologia restauradora busca um material que além de estético e resistente, tenha capacidade de aderir aos tecidos dentais mineralizados e que consiga restaurar os dentes de forma a impedir a microinfiltração marginal, diante das condições adversas do meio bucal (SILVA, E. O. S; et al. 2010).

Para obter um sistema adesivo ideal que atenda as características antagônicas do esmalte e dentina, diferentes tipos de sistemas adesivos estão disponibilizados no mercado odontológico aos cirurgiões-dentistas. Esses diversos sistemas podem ser classificados por gerações, pela forma de tratamento da smear layer (remoção total, parcial ou sem remoção) ou pelo número de passos clínicos (SILVA, E. O. S; et al. 2010).

Dentre os sistemas adesivos atualmente disponibilizados no mercado, pode-se dividi-los didaticamente em:

-sistemas adesivos convencionais de três passos; -sistemas adesivos convencionais de dois passos;

-sistema adesivo autocondicionante de dois passos;

- sistema adesivo autocondicionante de um passo (SILVA, E. O. S; et al. 2010).

Em 1955, Buonocore et al; foi o primeiro a demonstrar que o condicionamento ácido no esmalte com ácido fosfórico aumentava a forças de ligação resina-esmalte. E a partir de então as pesquisas só continuaram, demonstrando cada vez mais a eficiência e a necessidade de um bom condicionamento ácido do tecido.

Quando o processo de adesão se trata ao esmalte dental, pode-se dizer que este processo já é uma realidade; pois com o uso do ácido fosfórico aplicado sobre o tecido, ocorre a formação de microporosidades, que quando aplicado o monômero resinoso na fase seguinte e fotopolimerizado, resulta na retenção micromecânica do material restaurador ao substrato, que clinicamente é efetiva para a realização de inúmeros procedimentos nas diferentes especialidades odontológicas (SILVA, E. O. S; et al. 2010).

No caso da dentina foi preciso criar um material que apresentasse as características histológicas desse substrato; sendo assim, os sistemas adesivos são compostos por monômeros hidrofílicos compatíveis a umidade presente no tecido, e apresentam a fluidez necessária para penetrar nas microporosidades criadas pelo condicionamento ácido, além de possuírem monômeros hidrofóbicos, de maior peso molecular e maior viscosidade, que dão estabilidade e resistência mecânica ao produto (CARVALHO et al., 2004).

Foi em 1982, que Nakabayashi; Pashley, D. H; demonstraram que as resinas poderiam se infiltrar na dentina condicionada, e formar uma nova estrutura composta por uma matriz resinosa reforçada com fibras de colágeno. Esse novo biocompósito foi então nomeado de Camada Híbrida. Desde então, 
várias gerações de adesivos surgiram até a chegada dos sistemas denominados " autocondicionantes" (VAN MEERBEEK B; et al; 2007).

Frente a isso, este artigo visa através de uma revisão da literatura, descrever o processo de condicionamento ácido e sua importância, os sistemas adesivos tradicionais (etch-and- rinse), os sistemas adesivos autocondicionantes, relatando os pontos negativos e positivos de cada sistema, e o que o mercado odontológico dispõe de novidade para os cirurgiões- dentistas.

\section{Desenvolvimento}

Quando surgiu o conceito de condicionamento ácido total (esmalte e dentina), este foi recusado por diversos profissionais dos EUA e Europa, pois alegavam que o condicionamento ácido em dentina provocava reações adversas à polpa (FUSAYAMA, T; 1980). Mais tarde, foi relatado que o condicionamento ácido da dentina a mais de $0,5 \mathrm{~mm}$ de espessura não produzia reações pulpares adversas, e que o selamento da dentina condicionada poderia funcionar como uma barreira contra as bactérias orais e que as reações pulpares observadas nos EUA e na Europa correspondiam a infiltração bacteriana, e não a ação do ácido (PASHLEY, D.H. 1992).

A infiltração observada nos EUA e Europa, estava acontecendo pois os profissionais deste locais, estavam realizando o condicionamento ácido pela " ligação seca" na dentina. O processo de " ligação seca" consiste em secar as paredes das cavidades após o condicionamento ácido, afim de certificar que o condicionamento foi bem executado. Porém, na época não era sabido que a secagem da cavidade causava um colapso à dentina condicionada, sendo assim, a consequência foi que houve alta força de união resina-esmalte, e baixíssima força de união resina-dentina, que ao não resistir as forças de contração de polimerização, criava espaços que permitiam a infiltração bacteriana (ASMUSSEN, E; MUNKSGAARD, E.C; 1985).

Para tentar corrigir esse problema, foi introduzido o conceito de condicionamento úmido, que consiste em manter a dentina umedecida após o condicionamento, o que permite uma boa selagem e menor índice de dor pós-operatório (KANCA, J; 1992).

Para melhor compreender o processo de condicionamento ácido em dentina, é preciso conhecer a composição deste tecido dental.

A dentina é composta aproximadamente de 50\% de mineral, $30 \%$ de colágeno e $20 \%$ de água (NAKABAYASHI N, PASHLEY DH; 1998). Os $50 \%$ de minerais presentes na superfície e na sub superfície da dentina é solubilizado, extraídos e substituídos por água (durante a lavagem após condicionamento) que, quando combinado com os $20 \%$ de volume de água já 
presente no tecido, produz um novo teor de $70 \%$ de água. Durante a subsequente fase de infiltração de monômeros de ligação da resina, este $70 \%$ de volume de água deve ser substituído por $70 \%$ em volume de monômeros de resina, formando a camada híbrida ou zona de interdifusão (PASHLEY, D.H; HORNER, J.A; BREWER, P.O; 1992; CADENARO, M; et al; 2009).

No entanto, essa substituição de água por monômeros nunca é ideal, devido à presença de solvente residual, e devido ao movimento do fluido para fora dos túbulos dentinários nas misturas de monômeros hipertônicos, o que resulta na infiltração incompleta de monômeros resinosos nas matrizes de fibras de colágeno (PASHLEY, D.H; HORNER, J.A; BREWER, P.O; 1992; CADENARO, M; et al; 2009).

O tempo de aplicação do agente condicionador sobre o tecido dentinário é, em média, de 10 a 15 segundos, enquanto no esmalte é de 30 segundos. O aumento desse tempo de condicionamento em dentina pode expor túbulos dentinários e fibras colágenas que não serão totalmente impregnadas pelo monômero resinoso (LOPES et al., 2002).

Existem alguns condicionadores que apresentam compostos antimicrobianos como o cloreto benzalcônio, que inibem as metaloproteinases de matriz (MMPs) em dentina. Os iniciadores são normalmente água e soluções ricas de HEMA, que asseguram a completa expansão da malha de fibras de colágeno e molham o colágeno com monômeros hidrofílicos. No futuro, o etanol ou outros solventes isentos de água podem servir como iniciadores de desidratação que pode também conter metacrilatos de amônio quaternário (inibem MMPs) e aumentar a durabilidade das ligações resina-dentina. A evaporação completa dos solventes é quase impossível, sendo necessário uma otimização da concentração destes solventes pelos fabricantes, para que a evaporação destes, se aprimore com o tempo (PASHLEY, D. H; et al; 2011).

Segundo Tay, F.R; Gwinnett, J.A e Wei, S.H (1996) e posteriormente relatado por Cadenaro, M; et al. (2009), se a água e solventes remanescentes forem polimerizados junto com o adesivo, acarreta na produção de materiais com propriedades mecânicas inferiores.

Scott e Thomlinson (1998) mostraram que os solventes orgânicos, como o etanol e acetona, causam um colapso nos tecidos conjuntivos, removendo o teor de água. Com isso, diversos fabricantes dos sistemas adesivos tradicionais de 2 passos, começaram a dissolver os monômeros em etanol ou acetona, e não mais em água. Isto é porque os dimetacrilatos que utilizam os seus polímeros para endurecer por reticulação não são miscíveis com água, mas são solúveis em etanol.

Os sistemas com solventes como a acetona e o etanol necessitam da dentina mais 
úmida, o que torna esses sistemas mais sensíveis ao substrato dentinário seco (REIS, A; et al., 2001). Porém, o etanol permite que a dentina esteja levemente mais seca, resultando em uma maior amplitude no espectro de umidade ideal (REIS, A. et al.; 2003).

A remoção de grande parte dos solventes deve ser feito antes da fotopolimerização (YIU, C.K; et al.; 2005). O tempo clínico de 10 segundos, como é comumente recomendado, parece ser insuficiente para a evaporação mais elevada do solvente, sendo talvez necessário um tempo de até mesmo 24-96 horas (IKEDA, T; et al.; 2008).

De acordo com o trabalho executado por Moura, S.K; et al. (2014), o uso de uma corrente de ar quente melhora a resistência de ligação e reduz a nanoinfiltração das ligações entre resina e dentina.

Porém, é importante relatar que outros fatores como a variabilidade da dentina (superficial ou profunda) e o uso de materiais nanoparticulados, podem influenciar no desempenho de ligação dos adesivos à dentina (DI HIPOLITO, V.; et al. ;2012).

Hoje em dia pode-se encontrar três grupos de sistemas adesivos:os convencionais;os autocondicionantes; e os universais.

No sistema convencional, a face de união é obtida aplicando-se o ácido fosfórico previamente, seguido de lavagem, no qual o 'smear layer' é removido. No esmalte, esse procedimento forma microrretenções nas quais $\mathrm{o}$ adesivo pode penetrar $\mathrm{e}$ ser polimerizado (BRESCHI, L; et al; 2008). Na dentina, esse procedimento expõe os túbulos dentinários, tornando a dentina mais permeável aos fluidos (TAY, F.R; et al.; 2005). Essa técnica tem como desvantagem o aumento exagerado da permeabilidade da dentina, podendo gerar microinfiltração, o que reduz a qualidade da camada adesiva, podendo causar sensibilidade pós-operatória (TAY, F.R; PASHLEY, D.H; 2003).

Após o condicionamento, realiza-se a aplicação do primer, composto por monômero hidrofílico, como por exemplo o HEMA, que age preparando o substrato para receber um monômero hidrofóbico, presente nos adesivos dentários (REIS, A; et al.; 2007).

No sistema adesivo de dois passos, apresentam o condicionamento ácido como primeiro passo, seguido de lavagem, e no passo subsequente, a aplicação do primer+ adesivo. No caso, o primer e o adesivo encontram-se em um mesmo frasco, devido a união das duas substancias, o papel do primer pode ficar menos efetivo, sendo necessário uma aplicação ativa para auxiliar na penetração do adesivo e na evaporação dos solventes nele contidos (REIS, A; et al.; 2007).

A mistura dos monômeros e solventes no mesmo frasco, adicionados à agua presente no substrato (dentina) pode resultar em uma camada hibrida 
incompletamente infiltrada, devido a evaporação dos solventes e a presença de agua remanescente, tornando-a mais susceptível a degradação hidrolítica e proteolítica (SPENCER, P; et al.; 2000).

Os adesivos convencionais de três passos, no qual o primer e o adesivo encontram-se em frascos diferentes, pode-se encontrar os maiores índices de força adesiva. Neste caso, o primeiro passo, também é o condicionamento ácido, seguido de lavagem, porém o primer e o adesivo propriamente dito, encontram-se em frascos separados, não havendo interferência de um no efeito do outro (CLAVIJO, V; KABBAC, W; 2013).

No sistema adesivo autocondicionante, a etapa de condicionamento ácido previamente a aplicação do primer não existe; o "smear layer" 'é mantida e incorporado pelo adesivo, o que mantem a dentina pouco permeável (DE MUNCK, J; et al; 2005).

Esse tipo de sistema apresenta o primer ácido e quantidade relevante de solventes orgânicos para dar a fluidez suficiente para a solução infiltrar nos tecidos dentais, além de monômeros resinosos de baixa viscosidade, hidrofóbicos, semelhantes aos encontrados no sistema convencional de três passos (CARVALHO et al., 2004).

Apresenta como vantagem a possibilidade do controle da umidade dentinária, pois ao mesmo tempo em que ocorre a desmineralização da dentina, também ocorre a difusão dos monômeros, contribuindo para redução da sensibilidade pós- operatória, e obtenção de um melhor selamento dentinário (LAXE et al., 2007).

Uma outra característica dos adesivos autocondicionantes é a capacidade de união química que esses produtos apresentam à estrutura dental remanescente, dado comprovado por vários estudos, o que modificou por completo o conceito de adesão dos adesivos (VAN MEERBEEK, B; et al; 2011).

Os sistemas autocondicionantes apresentam um $\mathrm{pH}$ ácido que pode variar de 0.3 até 2.5 , os mais ácidos produzem uma camada híbrida mais espessa (VAN MEERBEEK, B.; et al.; 2011). Essa acidez é responsável pela qualidade de adesão ao esmalte, entretanto, este tipo de sistema ainda não é a melhor escolha quando se trata de adesão ao esmalte (CARDOSO, M.V; et al.; 2011).

Porém, esses sistemas autocondicionantes apresentam baixo índice de força adesiva ao esmalte, sendo recomendado o uso de ácido fosfórico neste tecido antes da aplicação do adesivo autocondicionante para tornar o esmalte mais poroso, aumentando a força de adesão a este tecido dental (SODRÉ, C. S; et al; 2013).

Os sistemas adesivos autocondicionantes de 2 passos: existe uma associação entre o primer ácido, que é aplicado primeiramente, seguido da aplicação 
do adesivo propriamente dito; encontrados em frascos separados. São exemplos destes sistemas: Clearfill SE Bond, Clearfill Protect Bond, Adhese, entre outros (SODRÉ, C. S; et al; 2013).

Já os sistemas de passo único ou 1 passo apresentam o primer ácido e o adesivo juntos no mesmo frasco, sendo aplicados diretamente sobre o substrato dentário. Alguns casos, pode-se encontrar o primer ácido e o adesivo em frascos separados, mas que são misturados antes de serem aplicados, com a finalidade de se evitar a alteração dos elementos fotossensíveis pela substancia ácida. São exemplos desses sistemas: Clearfill S3, Futurabons, G- Bons, Xeno V, entre outros (SODRÉ, C. S; et al; 2013).

Os sistemas autocondicionantes possuem monômeros funcionais responsáveis pelo condicionamento da superfície dentária, entre esses monômeros pode-se citar o 4META (ácido metacriloioxietil trimetílico), 10-MDP (10- Metacriloiloxidecil dihidrogênio fosfato) e Fenil-P (2Metacriloxietilfenil fosfato) como os mais comuns usados, interagindo com os cristais de hidroxiapatita de forma diversificada (VAN MEERBEEK, B.; et al.; 2011).

As moléculas de 10-MDP se aderem quimicamente ao cálcio da hidroxiapatita, mantendo os cristais de hidroxiapatita na interface adesiva, sendo dificilmente dissolvidos (VAN MEERBEEK, B.; et al.; 2011). A interação química existente, não resulta em aumento dos níveis de resistência adesiva, mas torna o material mais resistente ao processo de biodegradação (YOSHIDA,Y.; et al.; 2012).

As moléculas de Fenil-P e 4- META, se aderem inicialmente ao cálcio, mas são em seguida dissolvidas. É importante que os monômeros funcionais apresentem não apenas um potencial de adesão química, mas a capacidade de manter tais uniões estáveis (VAN MEERBEEK, B.; et al.; 2011).

Sabe-se que a dentina intertubular é a principal responsável pela formação da camada híbrida (PRATI et al., 1998); sendo que a parte mineral do dente sofre diversas variações ao decorrer do dente (ARAÚJO et al., 1995), ocorre também o aumento da espessura da dentina com a idade, e obstrução dos canalículos por deposição de cristais, tornando- se mais resistentes à soluções ácidas (EL KALLA \& GARCIA- GODOY, 1998).

Existem várias marcas que apresentaram ao mercado os adesivos universais, entre eles o adesivo Single Bond Universal (3M Espe) tem apresentado bons resultados clínicos e tem sido um dos mais estudados. $\mathrm{O}$ adesivo universal é um produto promissor, que pode ser utilizado como adesivo convencional, como autocondicionante de passo único, ou como condicionante seletivo para esmalte. É indicado para restaurações diretas e indiretas, sem a necessidade de aplicação de um primer 
metálico e silano. A sua exclusiva química possibilita a reidratação das fibras colágenas e a formação de uma camada híbrida mesmo com a dentina ressecada (3MESPE; 2014).

No aspecto clínico, Loguércio, Al.; et al. (2012), relatou que após 6 meses de uso clínico, o Single Bond Universal se mostrou confiável para ser utilizado, independentemente do modo pelo qual foi aplicado: condicionamento ácido total dentina úmida; condicionamento ácido total dentina seca; condicionamento seletivo em esmalte e autocondicionante.

Nos resultados de resistência de união em esmalte, com condicionamento seletivo, não apresentou diferença estatística quando comparado ao Clearfill SE Bond. No modo autocondicionante, também apresentou resultados estatisticamente iguais ao Clearfill SE Bond, e na técnica de condicionamento total, também foi igual ao Adper Scotchbond Multiuso Plus (FREITAS, M.S.; SHINOHARA, M.S.; DE GOES, M.F; 2012).

\section{Conclusão}

Com o desenvolver da tecnologia restauradora, e dos diversos produtos promissores presentes no mercado, é importante ressaltar que ainda não existe um sistema adesivo "perfeito", sendo importante avaliar as vantagens e limitações de cada sistema; além de se considerar o sistema de uso e aplicação do adesivo, pois o uso inadequado ou incorreto, implica sem dúvida, maiores chances de sensibilidade pós operatória e falhas prematuras da restauração.

Cabe ao profissional selecionar o tipo de sistema adesivo ao qual ele melhor se adapta, ao que melhor se aplica na situação clínica, assim como compreender os mecanismos de adesão, e modo de uso, a fim de obter o sucesso esperado no passo operatório.

\section{Referências}

BRESCHI, L; et al; Dental adhesion review: aging and stability of the bonded interface. Dent Mater; 24 (1):90-101; 2008.

BUONOCORE, M.G. A simple method of increasing the adhesion of acrylic filling materials to enamel surfaces. J Dent Res; 1955; 34: 849-53.

CADENARO M, et al; Effects of residual ethanol on the rate and degree of conversion of five experimental resins. Dent Mater; 25:621-8; 2009.

CARDOSO, M.V; et al.; Current aspects on bonding effectiveness and stability in adhesive dentistry. Aust Dent J; 56 Suppl 1:31-44; 2011.

CARVALHO, R. M. et al. Sistemas adesivos: fundamentos para a compreensão de sua aplicação e desempenho em clínica. Rev. Biodonto, v. 2, n. 1, p. 8-89, 2004.

CLAVIJO, V; KABBAC,W; Adesão : estratégias adesivas e o passo- a- passo para realizá-las. International Journal of Brazilian Dentistry; Florianópolis; v.9; n.4; p.374-383; out-dez; 2013.

DE MUNCK, J; e al.; A critical review of the durability of adhesion to tooth tissue: methods and results; J. Dent. Res; 84 (2):118-32; 2005.

DI HIPÓLITO V, Interaction morphology and bonds strength of nanofilled simplified-step 
adhesives to acid etched dentin. Eur J Dent; 6: 349-60; 2012.

EL KALLA, I.H.; GARCIA-GODOY, F. Bond strength and interfacial micromorphology of four adhesive systems in primary and permanent molars. J Dent Child, Chicago, v.65, n.3, p.169-176, May/June; 1998.

FREITAS, M.S.; SHINOHARA, M.S.; DE GOES, M.F. Effect of enamel pre-etching on bond strength of self-etching adhesives.

Dental Materials 28 S. v. 28, suppl. 1,p. e8e9; 2012.

FUSAYAMA T. New Concepts in Operative Dentistry. Tokyo: Quitessence Publishing Co., Inc.; pp. 61-156; 1980.

KANCA, J. Improved bond strength through acid-etching of dentin and bonding to wet dentin surfaces. J Am Dent Assoc; 123: 35$43 ; 1992$.

-LAXE, L. A. C. et al. Sistemas adesivos autocondicionantes. International Journal of Dentistry, v. 6, n. 1, p. 25-29, 2007.

LOGUÉRCIO, Al. et al. A new universal simplified adhesive: 6-month clinical evaluation. Journal of Esthetic and Restorative Dentistry. p. 1-5, 2012.

LOPES, G. C. et al. Dental adhesion: present state of the art and future perspectives. Quintessence Int. v. 33, n. 3, p. 213-224, 2002.

NAKABAYASHI, N; PASHLEY, D.H. Hybridization of Dental Hard Tissues. Chicago: Quintessence Publishing; pp. 65-67; 1998.

NAKABAYASHI, N; KOJIMA, K; MASUHARA, E. The promotion of adhesion by the infiltration of monomers into tooth substrates. J Biomed Mater Sci; 16:265-73; 1982.

MOURA, S. K; et al; The influence of air temperature for solvent evaporation on bonding of self-etch adhesives to dentin; Eur J Dent; 8:205-10; 2014.

PASHLEY, D.H. The effects of acid-etching on the pulpodentin complex. Buonocore Memorial Lecture; Oper Dent; 17: 229-42; 1992.

PASHLEY, D.H; HORNER, J.A; BREWER, P.O. Interactions of conditioners on the dentin surfaces. Oper Dent; 17(Suppl 5):127-50; 1992.

PASHLEY, D. H; et al. State of the art etchand-rinse adhesives. Dental materials; 27 ; $1-$ $16 ; 2011$.

PRATI, C.; CHERSONI, S.; MONGIORGI, R.; PASHLEY, D.H. Resin-infiltrated dentin layer formation of new bonding systems. Oper Dent, Seattle, v.23, n.4, p.185-194, July/Aug. 1998.

REIS, A. et al. Sistemas adesivos atuais. J BrasClin Odontol Int, v. 5, n. 30, 2001.

REIS, A.; et al.; Moisture spectrum of desmineralized dentin for adhesive systems with different solvent bases. J Adhes Dent; 5: 183-92; 2003.

REIS, A; et al.; Impact of adhesive application to wet and dry dentin on longterm resin- dentin bond streghts. Oper Dent; Jul-Aug; 32 (4); 380-7; 2007.

SCOTT, J.E; THOMLINSON, A.M. The structure of interfibrillar proteoglycan bridges ('shape modules') in extracellular matrix of fibrous connective tissues and their stability in various chemical environments. $\mathbf{J}$ Anat;192: 391-405; 1998.

SILVA, E. O. S.; BELTRANI, F. C.; SHIBAYAMA, R.; CONTRERAS, E. F. R.; HOEPPNER, M. G. Sistemas adesivos: conceito, aplicação e efetividade. Arq. Ciênc. Saúde UNIPAR, Umuarama, v. 14, n. 1, p. 81-87, jan./abr. 2010.

SODRÉ, C.S; et al.; Panorama dos materiais resinosos autocondicionantes \& autoadesivos. 
Revista APCD de Estética; 01(4): 402-411; 2013.

SPENCER, P; et al.; Interfacial chemistry of the dentin/adhesive bond. J Dent Res; 79: 1458-63; 2000.

TAY, F.T; GWINNETT,J.A; WEI, S.H. Micromorphological spectrum from overdrying to overwetting acid-conditioned dentin in water-free acetone-based, singlebottle primer/adhesive. Dent Mater; 12: 236$44 ; 1996$.

TAY, F.R; et al.; Water treeing- A potential mechanism for degradation of dentin adhesives- Deja vu? Open Dent; Sep-Oct; 30 (5); 561-79; 2005.

TAY, F.R; PASHLEY, D.H; Water treeing- A potential mechanism for degradation of dentin adhesives; Am. J. Dent. Feb. 16(1); 6-12; 2003.

VAN MEERBEEK, B; et. al; Techniquesensitivity of contempoary adhesives. Dent Mater J; 24(1); 1-13; 2005.

VAN MEERBEEK, B; et al.; State of the arte of self- etch adhesives; Dent Mater J; 27

(1):17-28; 2011.

YIU, C.K; et al. Solvent and water retention in dental adhesive blends after evaporation. Biomaterials; 26: 6863-72; 2005.

YOSHIDA, Y.; et al.; Self - assembled Nanolayering at the Adhesive interface. J Dent Res; 91:376-81; 2012.

3MESPE; Catálogo Completo Single Bond; 3MEspe; Universal; 2014. 